\title{
PLANNED OBSOLESCENCE: A KEYWORD ANALYSIS
}

\author{
DOI: 10.17261/Pressacademia.2020.1335 \\ JMML- V.7-ISS.4-2020(5)-p.227-233
}

\section{Baris Batuhan Gecit}

Beykent University, Department of International Trade, Istanbul, Turkey. batuhangecit@beykent.edu.tr, ORCID: 0000-0002-1354-1231

Date Received: November 2, 2020

Date Accepted: December 22, 2020

To cite this document

Gecit, B.B.,. (2020). Planned obsolescence: a keyword analysis. Journal of Management, Marketing and Logistics (JMML), V.7(4), p.227-233.

Permanent link to this document: http://doi.org/10.17261/Pressacademia.2020.1335

Copyright: Published by PressAcademia and limited licensed re-use rights only.

\begin{abstract}
Purpose - Marketing approaches have shifted towards consumer oriented approach throughout the 21st century and accordingly, marketing applications mainly tend to satisfy consumers and earn their trust. However, unethical applications may damage consumer satisfaction and trust. One of these unethical applications is planned obsolescence, which exists for years but became popular in recent years with some popular brands. This paper mainly aims to find out the most related keywords related to the popular term of recent years, planned obsolescence. After providing the relevant literature, history of planned obsolescence, planned obsolescence applications and types of planned obsolescence are provided in the literature section.

Methodology - After giving the relevant literature, keyword analysis has been used. To conclude the keyword analysis, 70 articles related to planned obsolescence have been downloaded from Scopus database. After downloading the relevant articles, VOS Viewer has been used for keyword analysis and germane keywords have been interpreted.

Findings - According to the keyword analysis, 28 items were found to be related to the planned obsolescence keyword. These keywords have been grouped as five clusters which are mainly related with; durability, sustainability, waste and product perishability. The fifth cluster includes two unrelated terms of consumer culture and environmental law. Without grouping clusters sustainability, sustainable development, economics, e-waste and product design are found to be the most frequently used keywords. Sustainability, sustainable development, and economics have the highest total link strength with planned obsolescence main keyword.

Conclusion - According to the keyword analysis conducted, keywords show that planned obsolescence has been determined to be related to negative consequences for both environment and consumers. Sustainability has found to be the most related keyword. As sustainable marketing is one of the popular concerns of the marketing discipline, unethical applications like planned obsolescence and sustainability come across. Additionally to sustainability; economics, product design are found to be the other most related keywords.
\end{abstract}

Keywords: Planned obsolescence, consumer behavior, marketing ethics, marketing, sustainability JEL Codes: M30, M31, M39

\section{INTRODUCTION}

Throughout the 20th century, marketing approaches have shifted from sales, product and production oriented approach to consumer-oriented approach. Marketing applications have aimed to satisfy consumers with obtaining trust, satisfaction and thus, loyalty. Even though marketing strategies have shifted from production and sales-centric to consumer-centric, some dominant brands still tend to obey consumer trust and satisfaction by applying unethical strategies thus some management and marketing applications do not necessarily satisfy consumer expectations. One of these unethical strategies is planned obsolescence. Planned obsolescence wears-off products before their actual life span with various methods to force consumers to repurchase the new products or force them to pay repair costs.

Planned obsolescence was initially discussed by Packard (1960), as an unethical strategy to design products which exulcerate untimely. Planned obsolescence is a strategic regulation of planning, designing, producing and manufacturing goods with restricted serviceable life (Erdil and Taçgın, 2019, 80). In other words, businesses plan their production mechanisms based on products becoming worn off during a certain period of time. Planned obsolescence is a business strategy for planning a product's 
aging period before becoming available on the market. The main goal of the firms while adopting this policy is to force customers to substitute goods they already own. Physical aging, aging in terms of efficiency, aging in terms of cosmetic longevity, aging by limiting repairability, systemic aging, technical aging, delayed aging and aging related to fashion are distinct forms of obsolescence (Akçay, 2018). Businesses that apply planned obsolescence can be called "waste makers" (Packard and McKibben, 1963).

Even though planned obsolescence is an unethical term for businesses; obsolescence is a positive word for most disciplines. For disciplines like architecture, art or novelty; obsolescence has a historical and positive meaning. However, for marketing discipline this circumstance is not the same. Obsolescence causes some extra spending for consumers, many waste products for the environment, and negative consequences for good producers.

Durable goods-producing businesses may face competition from the units used because of the long-lasting nature of the products. To overcome such competition, firms may "kill off" used units by introducing newer versions of the product, making the used units economically obsolete. This application is planned obsolescence (lizuka, 2007, 191).

\section{LITERATURE REVIEW}

\section{1. Planned Obsolescence Cases in the History}

There is a famous lamb produced by Shelby Electric Company, still lighting for more than 100 years. This is an excellent example of a non-obsolescence. However, it is now challenging to find a lamb that lights for more than a couple of years. Even though technology has advanced dramatically in the last 100 years, a lamb that has been created with a relatively deficient level of technology era lighted for more than 100 years. This is mainly caused of the planned obsolescence, as companies do not tend to produce long-living products. Not necessarily every company applies planned obsolescence, but there are lots of companies that tend to use it.

Another brand that can be a good example is DuPont. DuPont was producing low-quality products and could not satisfy consumers before the era of World War II. The low quality of nylon stockings in its early design did not satisfy the female public. DuPont started cooperating to achieve military goals and applied the knowledge it had treasured about nylon fibre to develop more potent derivatives. The nature of nylon justified that the product could be used for long periods and this troubled DuPont and other companies that had entered into the same market. Gradually, the quality of stocking diminished. In the U.S., demonstrations evolved against what they understood as "social insensibility" because they did not provide fair conditions for a useful product for women. This resulted in significant media pressure toward DuPont, and they were directed to increase the quality. The material reached very high standards and until the end of the 40 s were transposed into the market, making available a quality and durable product (Monteiro, 2018, 23).

In earlier literature for planned obsolescence, it is mainly focused on the "monopoly" keyword (Swan, 1972, 575) and the "automotive" sector (Rodabaugh, 1966; Flink, 1972; Sherif and Rice, 1986). Monopoly is a frequent keyword because, especially for sectors with monopoly or relatively monopoly, powerful brands can find themselves in a position almost to act as however they want. Imagine an almost impossible scenario, where there is only a single automotive manufacturer in the World. For this scenario, the brand may apply planned obsolescence as there are no rivals to threaten them.

Automotive industry is another frequently used keyword for planned obsolescence because as academic literature regarding planned obsolescence has started with 1910's; the first planned obsolescence applications in the business world has been observed. In the 1910's and 1920's automotive industry has been a critical factor for planned obsolescence, with brands such as Ford and Chevrolet applied this strategy. During the late 1950's these two brands have once again been key actors for planned obsolescence in the automotive industry (Packard and McKibben, 1963, 52).

In the early 1990's, IBM has altered the operating system used in its personal computers by reducing the compatibility between its old and new computers (Waldman, 1993, 273). It has been one of the earlier cases of planned obsolescence in technology.

Printer brands such as Epson, HP, Canon and Brother was sued for forcing consumers to change printer inks before they completely finish. In 2014, France even passed "Hamon Law" which put some practices on planned obsolescence. France has been the first country to adopt a resolution against planned obsolescence (Schrieberg, 2017).

Another investigation regarding planned obsolescence has proceeded in Italy against Samsung and Apple. To decide whether two prominent mobile makers use software upgrades to hurry smartphones to influence consumers to upgrade their phones. According to the community, Apple and Samsung do not give consumers adequate information on the impact of software upgrades. They do not include specifics of how they could slow down installation of devices which it claims could breach many Italian consumer protection code posts (Gartenberg, 2018). 
Recently, Apple's planned obsolescence has been an infamous case. Known as "the Batterygate"; Apple slowed down batteries of older smartphones. Some Apple users have already been claiming that Apple was intentionally slowing down older phones and probably they were right. After a lawsuit in 2020, Apple has been accused of slowing down older mobile phones and settling to pay a $500 \mathrm{M} \$$ compensation, while paying $25 \$$ for each old iPhone user who has applied to get paid for compensation. This one has been one of the most sensational planned obsolescence cases (Nicas, 2020).

Consumer responses were conclusive on a few occasions. Many may also opposed Apple in far more situations exposed than they wanted. Even though such practices were simple and specifically targeted at one more step in obsolescence, they were approved and embraced by customers. Indeed, customers have even protected planned obsolescence in some instances. This is Apple's more astonishing accomplishment in the production sector since it has persuaded parties that this is a successful strategy, mindful of its obsolescence. At the same time, it goes against their own interests (Pineda and Salmoral, 2017, 24). This is a good example of brand advocacy. Brand advocacy happens when consumers feel very passionate about a brand, seek to promote it to others and defend it against its naysayers (Wilder, 2020). Consumers defend the brands which are favorable to them like they are the advocates of the brand. However even if some consumers defend the brands they are fanatically loving, some consumers may get discouraged and feel disappointed by such applications. Apple's smartphone market share can provide ample proof for this. According to Statista (2020), Apple has been the second brand of smartphone market in terms of market share for most of the 2010's. Till 2020, Apple has been competing with Samsung for the first spot, sometimes passing their rivals, but mostly being dominated by Samsung in terms of market share. However with the second half of the 2020, Chinese brands Huawei and Xiaomi got more vital in the smartphone market and become the 2nd and 3rd brands of smartphone market in terms of market share. According to the latest report of Statista regarding smart phone market shares; Samsung is the leader of the market with \%22.7, Huawei is second with \%14.7, Xiaomi is third with \%13,1 and Apple become fourth with \%11.8 market share (Statista, 2020). These market shares are lower than the era of early 2010's, where Nokia and Blackberry were market leaders and Apple was attacking aggressively to dominate the market. These numbers might be consequences of Apple's planned obsolescence, additionally to their high pricing strategies relative to their rivals.

\subsection{Consumer Regulations and Types of Planned Obsolescence}

As mentioned above, consumer protection regulations have been applied in some countries to avoid the ill-usage of brands. Relatively to consumer protection applications, another subject is the balance of unequal relation in consumption (Pineda and Salmoral, 2017, 39).

Excessive consumptive activity on the consumer's side has arisen from the affluent's monopoly and extended to the base of society. Planned obsolescence strategy increases the rate of consumption as a tool of consumption culture.

There is a marketing term of "purchase frequency" which means how repetitive consumers are making the purchase. As businesses apply planned obsolescence, purchase frequency increases; thus dynamics of consumer behavior sub-discipline change. An unethical approach of businesses to wear out products affects the frequency of consumers. Without a doubt, planned obsolescence is not the only factor that affects how frequently consumers purchase. Owning a luxurious product means representing a prestige, communicating social status and impressing others like peers for some consumers (Abid and Abbasi, 2014, 3). Consumers may tend to purchase the newest iPhone, Nike shoes or any other thing that represents luxury for them to show off their status.

Planned obsolescence can actually be applied with various methods. Cooper (2004) has divided obsolescence into; psychological obsolescence, economic obsolescence and technological obsolescence. Technological obsolescence arises when people are attracted to functions in newer models added or changed due to advances in knowledge. As new screen technologies have been introduced, older televisions become out of date. Especially tube televisions have got out of date with the introduction of LCD, Led televisions. Psychological obsolescence is about the attractiveness and satisfaction level of newer products. As new products are more attractive and satisfy consumers more, this kind of obsolescence happens. Throughout the recent years in the automotive industry, there have been dramatic design innovations for both the internal and external automobiles. As the 2020 year, designs of 2020 model automobiles are incredibly stylish compared to automobiles which are not counted as older cars like 2015 to 2017 model automobiles. Economic obsolescence is the loss of economic value of the product kept by consumers. If a product's value decreases dramatically with new introduced products or other factos, economic obsolescence would likely occur.

These methods are the sources of obsolescence and businesses professionally apply these planned obsolescence categories to their production strategies. If countries continue applying legislation to avoid planned obsolescence and protect consumers, businesses' obsolescence strategies may be interrupted. But these applications still exist and to analyze which concepts are mostly used regarding planned obsolescence, a keyword analysis is applied. 


\section{KEYWORD ANALYSIS}

Keyword analysis is an important research theme in bibliometrics (Wang and Chai, 2018, 721) and became a popular analysis method in recent years with analyzing texts via computer assistance (Seale and Tonkins, 2012). Keyword analysis represent the author's opinion of several most essential words in their articles and potentially detect trending research topics. Additionally keyword analysis reveals research topics that are most frequently used, association of keywords and likelihood of them (Pesta et al., 2018, 2). Keyword analysis is mainly a literature review methodology, applied via computer programs with using networks and occurrences.

With keyword analysis, it is aimed to observe the most relevant factors regarding planned obsolescence concept. Additionally, to relevant factors, the occurrence of these factors and link strengths are aimed to be observed with an analysis conducted via VOS Viewer (van Eck and Waltman, 2020). Meaning and application of these terms have been given below Figure 1.

Over the past 15 years, Web of Science, Scopus, and Google Scholar have been the three most important multidisciplinary bibliographic data sources, providing metadata on scientific documents and citation links between them. Therefore, WoS and Scopus have long been the only options for large-scale bibliometric studies (Visser et al., 2020, 1).

Planned obsolescence term have been used to collect data and marketing related articles of planned obsolescence keyword have been downloaded from the Scopus database. The downloaded database has been analyzed with a co-occurrence network option. The basic premise is clearly that terms with similar meanings seem to arise in typical ways, and thus, co-occurrence statistics should provide a natural base for semantic representations (Bullinaria and Levy, 2007, 510).

The results retrieved included 70 documents from Scopus. Documents from 1974 to 2020 were retrieved. Articles unrelated to marketing and related to engineering or economics have been excluded as this article is a marketing article.

Keyword co-occurrence network is formed when keywords of specific articles form a relationship (Khan and Wood, 2015, 962). A network map of co-occurrences is given below.

\section{Figure 1: Keyword Network}

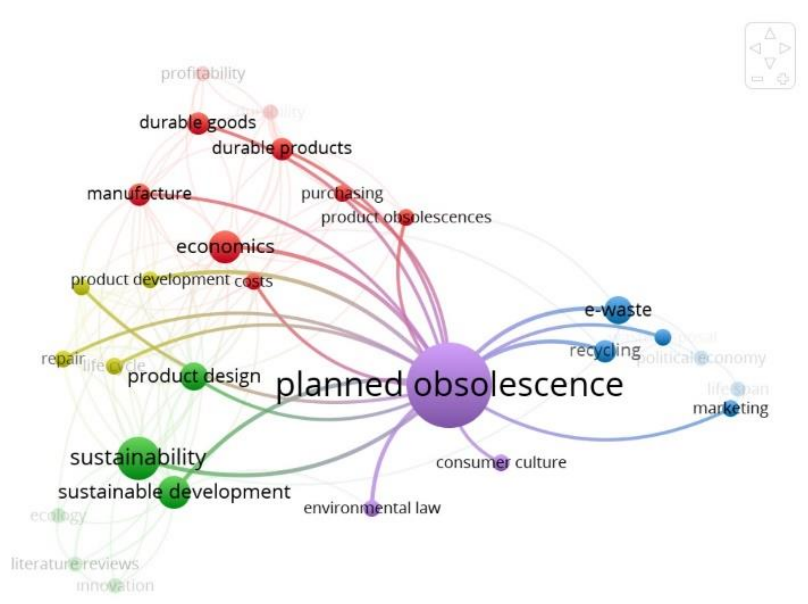

Figure 1 includes the most relevant keywords to planned obsolescence keyword. The methodology of Vos Viewer application is to list these keywords via co-occurences of these keywords and link strength of these keywords. Co-occurrences mean how frequently these keywords are used in articles. For example sustainability keyword has been found to occur seven times. This means sustainability keyword is used at seven of seventy total articles. For a given item, the Links and Total link strength attributes indicate, respectively, the number of links of an item with other items (van Eck and Waltman, 2020, 6).

Twenty-eight items are found to be related to planned obsolescence keyword. These twenty-eight items have been clustered into five categories. These categories are seen with different colors in the network map. There have been 118 links between all related keywords and total link strength of these keywords is 151. From the network map, keywords with bolder relation arrows are related more powerfully. 
As it might be difficult to differentiate these keywords from the map and give their clusters, links, total link strengths and occurrences; the keyword analysis table has been given below.

Table 1: Results of Keyword Analysis

\begin{tabular}{|c|c|c|c|c|}
\hline Keyword & Cluster & Links & Total Link Strength & Occurrences \\
\hline Profitability & 1 & 5 & 5 & 2 \\
\hline Durable Goods & 1 & 7 & 7 & 3 \\
\hline Durability & 1 & 9 & 11 & 2 \\
\hline Durable Products & 1 & 10 & 12 & 3 \\
\hline Manufacture & 1 & 14 & 16 & 3 \\
\hline Purchasing & 1 & 7 & 7 & 2 \\
\hline Product Obsolescence & 1 & 8 & 8 & 2 \\
\hline Economics & 1 & 18 & 25 & 5 \\
\hline Costs & 1 & 14 & 16 & 2 \\
\hline Product Design & 2 & 16 & 24 & 4 \\
\hline Sustainability & 2 & 14 & 24 & 7 \\
\hline Sustainable Development & 2 & 14 & 23 & 5 \\
\hline Ecology & 2 & 4 & 4 & 2 \\
\hline Innovation & 2 & 4 & 4 & 2 \\
\hline E-Waste & 3 & 5 & 7 & 4 \\
\hline Recycling & 3 & 6 & 8 & 3 \\
\hline Political Economy & 3 & 4 & 4 & 2 \\
\hline Life Span & 3 & 2 & 2 & 2 \\
\hline Marketing & 3 & 2 & 2 & 2 \\
\hline Waste Disposal & 3 & 4 & 4 & 2 \\
\hline Cost Effectiveness & 4 & 10 & 11 & 2 \\
\hline Repair & 4 & 10 & 14 & 2 \\
\hline Product Development & 4 & 11 & 12 & 2 \\
\hline Life Cycle & 4 & 10 & 14 & 2 \\
\hline Environmental Law & 5 & 2 & 3 & 2 \\
\hline Consumer Culture & 5 & 1 & 1 & 2 \\
\hline
\end{tabular}

According to the table, there have been five clusters. The first cluster includes profitability, durable goods, durability, durable products, manufacture, purchasing, product obsolescence, economics and costs. These terms are mainly related to durability and economics\&finance. As one of the main keywords related to planned obsolescence is durability, it is an obvious keyword for planned obsolescence. Planned obsolescence concerns about durability decisions (Waldman, 1996, 584). Especially link strengths of durability, durable goods and manufacture are relatively high. Thus these terms are positively linked with planned obsolescence.

The second cluster contains product design, sustainability, sustainable development, ecology and innovation terms. These terms are mainly related with sustainability. The main aim of sustainable marketing is to achieve financial goals while being sensitive for social and environmental responsibilities (Pogrebova et al., 2017, 694). As planned obsolescence results in more frequent production, more frequent purchase for consumers thus more waste products, it directly contradicts with sustainability and 
sustainable marketing. As total link strengths and occurrences of sustainability keywords are high, this term is strongly and frequently related to planned obsolescence.

The third cluster has e-waste, recycling, political economy, life span, marketing and waste disposal keywords. These terms are mostly related to waste. Political economy and marketing keywords represent both politics, economics and marketing strategies are mentioned in related articles. The waste term can also be related to sustainability and the second cluster. Whether it is food waste, water waste or product waste; sustainability has always been a related issue for marketing literature.

The fourth cluster includes cost effectiveness, repair, product development and life cycle keywords. These terms are mainly related to product perishability. As life cycles of worn-out products' ends, these products require repair, which causes extra costs for consumers. Repair can be an additional cost for consumers without repurchase if the brand is also the product's service supplier. Brands can both be the vendor and the repair service of products and create another cost for the consumer. These terms are also related to first cluster and durability.

The fifth and final cluster contains only two keywords. These are consumer culture and environmental law. Planned obsolescence has been a critique concept for consumer culture as brands try to accelerate consumers' consumption (Wieser, 2016, 156). As mentioned early at the waste concept, environmental law is also another keyword related to planned obsolescence. Some measures have to be taken regarding these strategies to save to the environment. As mentioned in the literature section, some countries like Italy and France have taken some steps towards planned obsolescence with applying legal measures.

\section{CONCLUSION}

Planned obsolescence has been used by several popular brands throughout the history and more frequently in recent years. Even there are many non-academic articles regarding this unethical term. Marketing literature related to this word is not so extensive, which can be proven by the fact that there could only been found 70 articles worldwide about the marketing perspective of planned obsolescence. In most articles that apply keyword analysis, writers utilize more amount of articles. From these seventy articles, there have been 28 keywords found to be related to planned obsolescence. Among these, keywords grouped at sustainability cluster are found to be the most related keyword. Sustainable marketing is a popular term of marketing both in practice and academics and offers a market philosophy of sustainable development to create a model of responsibility towards consumers (Pogrebova et al., 2017, 694). As marketing faces criticisms regarding its profit based mentality and approach (Seretny and Seretny, 2012, 1), unethical applications like planned obsolescence can severely damage the brand image; whereas ethical perceptions like sustainable marketing can empower the brand image. As sustainability and planned obsolescence are at crosspurposes, negative consequences of planned obsolescence is a concern for sustainability.

Brands that become more dominant in a particular market may tend to apply unethical strategies like planned obsolescence. It has so many consequences for either society, ecology and business world. Keywords founded via keyword analysis are mainly concerned with environment, waste, sustainability, durability, repair, and worn-off products' costs. As more people will be forced or weighed on to purchase new products, more waste products will be. Thus environment and sustainability will get hurt.

There will be economic consequences and consumers will spend more on both new products or repairing existing products. As brands put on the market frequently, this can also create consumption inequality as people may tend to purchase frequently to feel social privilege.

Even top brands may have high brand images, thus have high consumer loyalties. Every brand can lose these advantages with wrong marketing strategies. Such an unethical marketing strategy has so many negative consequences, not only dangerous for the environment, consumption culture and other related factors, but also threatening for the brand itself.

\section{REFERENCES}

Abid, M. and Abbasi, M. (2014). Antecedents and outcomes of consumer buying attitude; the case of Pakistani counterfeit market. Indian J. Sci. Res, 8(1), 165-176.

Akçay, V.H. (2018). Planlı Eskitme Stratejisi Üzerine Araştırmalar, Sosyo-psikolojik bir değerlendirme. Ankara: Gazi Kitabevi.

Bullinaria, J. A. and Levy, J. P. (2007). Extracting semantic representations from word co-occurrence statistics: A computational study. Behavior research methods, 39(3), 510-526.

Cooper, T. (2004). Inadequate life? Evidence of consumer attitudes to product obsolescence. Journal of Consumer Policy, 27(4), 421-449.

Erdil, P. A. and Taçgın, E. (2019). An Overview of the Planned Obsolescence Paradigm-Marketing Strategy: Evaluation via Multiple Criteria Decision Making Methods For The Sectors in Turkey. International Congress Of Management Economy and Policy 2019 Spring Proceedings Book.

Flink, J. J. (1972). Three stages of American automobile consciousness. American Quarterly, 24(4), 451-473. 
Gartenberg, C. (2018). Apple and Samsung are both under investigation by the Italian government over planned obsolescence. https://www.theverge.com/2018/1/18/16906658/apple-samsung-investigation-italian-antitrust-planned-obsolescence-software-slowdown Access Date: 30.11.2020.

lizuka, T. (2007). An empirical analysis of planned obsolescence. Journal of Economics \& Management Strategy, 16(1), $191-226$.

Khan, G. F. and Wood, J. (2015). Information technology management domain: emerging themes and keyword analysis. Scientometrics, 105(2), 959-972.

Monteiro, V. (2018). Does the planned obsolescence influence consumer purchase decisions? The effects of cognitive biases: bandwagons effect, optimism bias on consumer behavior. Fundação Getulıo Vargas Escola De Admınıstração Do Estado De São Paulo.

Nicas, J. (2020). Apple Agrees to Pay Some iPhone Owners \$25 Each. New York Times. https://www.nytimes.com/2020/03/02/technology/appleiphone-lawsuit-settlement.html Access Date: 26.11.2020.

Packard, V. (1960). The Waste Makers. New York: David McKay Company.

Packard, V. and McKibben, B. (1963). The Waste Makers. Harmondsworth: Penguin books.

Pineda, J. A. S. and Salmoral, M. P. (2017). A juridical “theory” of planned obsolescence. SSRN.

Pesta, B. Fuerst, J. and Kirkegaard, E. O. (2018). Bibliometric keyword analysis across seventeen years (2000-2016) of intelligence articles. Journal of Intelligence, 6(4), 46.

Pogrebova, O. A., Konnikov, E. A. and Yuldasheva, O. U. (2017, May). Fuzzy model assessing the index of development of sustainable marketing of the company. In 2017 XX IEEE International Conference on Soft Computing and Measurements (SCM) (pp. 694-696). IEEE.

Rodabaugh, J. H. (1966). Idol of the West: The Fabulous Career of Rollin Mallory Daggett.

Schrieberg, D. (2017). Landmark French Lawsuit Attacks Epson, HP, Canon And Brother For 'Planned Obsolescence'. Forbes.com. https://www.forbes.com/sites/davidschrieberg1/2017/09/26/landmark-french-lawsuit-attacks-epson-hp-canon-and-brother-for-plannedobsolescence/?sh=29e9da61b36a . Access Date: 30.11.2020.

Seale, C. and Tonkiss, F. (2012). Content and comparative keyword analysis. Researching society and culture. 459-478.

Seretny, M. and Seretny, A. (2012). Sustainable Marketing-a new era in the face of social, economic and environmental change. Foundations of Management.

Sherif, Y. S. and Rice, E. L. (1986). The search for quality: The case of planned obsolescence. Microelectronics Reliability, 26(1), 75-85.

Swan, P. L. (1972). Optimum durability, second-hand markets, and planned obsolescence. Journal of Political Economy, 80(3, Part 1), 575-585.

Van Eck, N. J. and Waltman, L. (2020). VOSviewer Manual. Leiden University.

Visser, M., van Eck, N. J. and Waltman, L. (2020). Large-scale comparison of bibliographic data sources: Scopus, Web of Science, Dimensions, Crossref, and Microsoft Academic. arXiv preprint arXiv:2005.10732.

Waldman, M. (1993). A new perspective on planned obsolescence. The Quarterly Journal of Economics, 108(1), $273-283$.

Waldman, M. (1996). Planned obsolescence and the R\&D decision. The RAND journal of Economics, 583-595.

Wang, M. and Chai, L. (2018). Three new bibliometric indicators/approaches derived from keyword analysis. Scientometrics, $116(2)$, $721-750$.

Wieser, H. (2016). Beyond planned obsolescence: Product lifespans and the challenges to a circular economy. GAIA-Ecological Perspectives for Science and Society, 25(3), 156-160.

Wilder, K. M. (2020). Brand advocacy: Conceptualization and measurement. Mississippi State University. 